\title{
Patterns of physician retirement and pre-retirement activity: a population- based cohort study
}

Lindsay Hedden PhD, M. Ruth Lavergne PhD, Kimberlyn M. McGrail PhD, Michael R. Law PhD, Lucy Cheng MSc, Megan A. Ahuja MPH, Morris L. Barer PhD

Cite as: CMAJ 2017 December 11;189:E1517-23. doi: 10.1503/cmaj.170231

Visual abstract available at www.cmaj.ca/lookup/suppl/doi:10.1503/cmaj.170231/-/DC1

See related article at www.cmaj.ca/lookup/doi/10.1503/cmaj.171302

\begin{abstract}
BACKGROUND: Knowing when physicians retire and how they practise in the pre-retirement years is important information for health human resource planning. We identified patterns of retirement for physicians in British Columbia and the determinants of when and how physicians retire.
\end{abstract}

METHODS: For this population-based retrospective cohort study, we used administrative data to examine activity levels and to identify retirements among BC's practising physicians. We included all physicians who were at least 50 years of age as of March 2006 and who had received payments for clinical services in at least 1 year between 2005/06 and
2011/12. We defined retirement as a permanent drop in monthly payments to less than $\$ 1667 /$ month ( $\$ 20000 / y r)$. We examined the patterns and timing of retirement by age, sex, specialty and location using linear and logistic regression models.

RESULTS: Of the 4572 physicians who met the inclusion criteria, 1717 (37.6\%) retired during the study period. The average age at retirement was 65.1 (standard deviation 7.8) years. Controlling for other demographic and practice characteristics, we found that women and physicians working in rural areas retired earlier, by 4.1 (95\% confidence interval [Cl] -4.9 to -3.2$)$ years and $2.3(95 \% \mathrm{Cl}-3.4$ to -1.1 ) years, respectively. We found no dif- ference in retirement age by specialty. We identified 4 patterns of pre-retirement activity: slow decline, rapid decline, maintenance and increasing activity. About $40 \%$ of physicians $(440 / 1107)$ reduced their activity levels by at least $10 \%$ in the 3 years preceding retirement.

INTERPRETATION: During the study period, physicians in $\mathrm{BC}$ - particularly women and those in rural areas retired earlier than indicated by licensure and survey data. Many physicians reduced their practice activity in the pre-retirement years. These trends indicate that forecasts relying on licensure "head counts" are likely overestimating current and future physician supply.
$\mathbf{P}$

hysician supply is a perennial preoccupation in Canada. Effective and accurate physician workforce planning requires data on how many physicians are being trained and in what specialties, combined with information on physicians' clinical activity over the work life cycle, particularly as they are nearing retirement. ${ }^{1}$ These data are also relevant for clinicians themselves. Retirement represents a complex transition for physicians, who are balancing financial considerations with workload, work identity, personal health, spousal employment and a sense of responsibility to their panels of patients., ${ }^{2,3}$ Heavy workload and burnout are commonly cited as reasons for early retirement, whereas ongoing financial obligations may delay the transition to retirement. ${ }^{4}$ Furthermore, early retirements may increase the pressure on those not retiring to take on additional patients or provide additional services. This, in turn, may affect rates of physician burnout and the ability to maintain an appropriate work-life balance.

Although substantial attention has been directed toward physician supply more broadly, there has been relatively little research examining retirement patterns or pre-retirement clinical activity. Most existing evidence relies on surveys, in which physicians are asked about their intention to retire within a set future period of time..$^{5-8}$ Data from 2013 suggested that $15 \%$ of Canadian family physicians and $12 \%$ of other specialists (repre- 
senting $53 \%$ of physicians aged 65 or older) intended to retire between 2014 and $2016 .{ }^{9}$ An additional $30 \%$ of all physicians surveyed planned to reduce their hours, and $13 \%$ planned to reduce their scope of practice. ${ }^{9}$

There is limited empiric evidence about the relation between these self-reported intentions and actual changes in clinical activity. Where such evidence exists, it suggests that selfreporting projects a substantially higher rate of retirement (and at an earlier age) than has been observed using licensure data. ${ }^{10,11}$ However, where self-reporting may overestimate retirements, licensure data may underestimate them, either because of a lag in obtaining up-to-date information ${ }^{12}$ or because physicians may maintain active licences without delivering any substantial quantity of clinical care..$^{10,11}$

Understanding what physicians are doing in the years leading up to retirement is also important, and literature in this area is similarly limited. Survey data suggest that $90 \%$ of physicians would prefer to retire gradually, reducing clinical workload over time, rather than stopping work completely. ${ }^{13}$ This is consistent with a recent analysis of payment data, which suggested that physicians' workloads decline and scopes of practice narrow after age $65 .^{10}$

In this study, we analyzed physician retirements and preretirement activity using payment data, which addresses the shortcomings of both self-reported and licensure data by measuring actual practice activity. We identified the patterns and determinants of retirement and pre-retirement activity among all physicians 50 years of age or older practising in British Columbia.

\section{Methods}

\section{Data sources}

In this population-based, retrospective cohort study, we used administrative data to describe physician retirements and preretirement activity. We used physician payment files from BC's Medical Services Plan for fiscal years 2005/06 to 2011/12 to track fee-for-service payments at the physician level. ${ }^{14}$ We also incorporated data from the BC Ministry of Health's Alternative Payment Program database, which tracks non-fee-for-service payments to physicians, including salary, service contracts, sessional fees and other forms of payments..$^{15}$ These 2 data sets together encompass $100 \%$ of the clinical payments made to physicians in the public health system during the study period. To focus on changes in levels of activity, we removed the effects of fee changes by valuing all fee-for-service payments to physicians at 2012 fee levels. We adjusted payments from the Alternative Payment Program to 2012 dollars using the consumer price index.

Data in the physician payment files are recorded as unique combinations of physician, patient, service and date. Data in the Alternative Payment Program database, by contrast, are recorded on an annual basis at the physician level. To estimate monthly payment amounts from the Alternative Payment Program, we divided each physician's payments from that program by the number of months they were active in the Medical Services Plan data set. For physicians who had no fee-for-service payments but were still active within the Alternative Payment
Program database, we divided their annual payments by the number of months they maintained an active practice licence.

We obtained demographic information about physicians including age, sex, specialty and practice location - from the College of Physicians and Surgeons of British Columbia. ${ }^{16}$ We classified practice location as rural-dominated (health service delivery area having no city with population $>75000$ or having less than $75 \%$ of the population in a defined census metropolitan area ${ }^{17}$ ), urban-dominated (health service delivery area having at least 1 city with population $>75000$ and in which at least $75 \%$ of the population lives in a census metropolitan area) or metropoli$\tan$ (health service delivery area in which $>90 \%$ of population lives in census metropolitan area with population > 75000).

\section{Study population}

We started with the complete population of physicians in $\mathrm{BC}$ who received any income through fee for service or the Alternative Payment Program for clinical practice in at least 1 year between 2005/06 and 2011/12 and who were aged 50 years or older as of Mar. 31, 2006. Age 50 was selected as the cut-off to ensure we were not introducing an upward bias into our calculated average retirement age by choosing a cut-off that was too close to "normal" retirement age. We also wanted to ensure that we could examine physicians' activity levels in the years that preceded a retirement transition. We excluded individuals who practised out of province or had opted out of public practice, as well as those whose licences were suspended and those who died.

\section{Identification of retirement}

We conceptualized retirement as the cessation of substantial clinical activity, not necessarily the complete absence of clinical activity and income. From this perspective, we assumed that a physician who billed for very few patient consultations was effectively retired. We tested a variety of payment thresholds to identify retirement events, varying the threshold between $\$ 0$ and $\$ 40000$ annually (\$0 to $\$ 3333$ per month). Correlations among the different payment thresholds tested was high $\left(r^{2}\right.$ range 0.86 to 0.93 ), and varying the threshold changed only slightly the number of physicians identified as retiring and did not affect either the direction or significance of the regression results.

Given these threshold-invariant preliminary results, we elected to use the moderate threshold of $\$ 20000$ as our retirement definition: if and when a physician's monthly payments fell and remained below $\$ 1667$ (\$20000 annually) for the rest of the study period, that physician was flagged as having retired in that month.

\section{Pre-retirement activity trajectories}

To examine patterns of practice in the years preceding retirement, we refined our cohort to include only those individuals for whom we had 3 full years of practice activity (payments greater than $\$ 0$ ). We computed the average slope of billing activity in those years and identified 4 mutually exclusive and exhaustive patterns: increase (an increase in activity of $10 \%$ or greater), maintenance (limited change in activity $[ \pm<10 \%]$ ), slow decline (a decline in activity of $10 \%$ to $<25 \%$ ) and rapid decline (a decline 
in activity of $25 \%$ to $<90 \%$ ). We found no frequently occurring patterns of pre-retirement activity that did not fit within 1 of these 4 categories.

\section{Statistical analysis}

We examined whether the propensity to retire differed by specialty grouping (primary care, medical specialty, surgical specialty or laboratory/imaging specialty) or physician demographic characteristics (sex, age, rurality of practice location, training location) using $\chi^{2}$ tests. We modelled propensity to retire using a multivariable logistic model, including the same list of clinical and demographic covariables.

For physicians who retired during the study period, we used a multivariable linear regression to determine the association between age at retirement and physician sex, specialty, training location and practice location.

Finally, we examined the frequency of pre-retirement activity patterns within the subgroup of physicians for whom we had 3 years of activity, and explored the relation between identified trajectories and clinical and demographic characteristics.

\section{Ethics approval}

This study was approved by the University of British Columbia Behavioural Research Ethics Board.

\section{Results}

A total of 4854 physicians met the initial inclusion criteria. We excluded a total of 282 individuals, which left a final cohort of 4572 physicians (Figure 1). Of the final cohort, 3658 (80.0\%) were men, $2193(48.0 \%)$ were aged 65 or over by the end of the study period, and 518 (11.3\%) were aged 75 or over by the end of the study period (Table 1). Annual all-source clinical payments averaged \$270 000 in 2012 Canadian dollars. A total of 2976 physicians (65.1\%) practised in metropolitan centres, and 2925 (64.0\%) had trained within Canada.

\section{Retirement}

A total of 1717 (37.6\%) of the physicians retired during the study period. An additional 486 (10.6\%) dipped below the threshold of clinical activity before returning to active practice; of these, 226 (46.5\%) remained inactive for at least 1 full year before their return.

Adjusting for other demographic and clinical characteristics, female physicians had 1.7 times greater odds of retiring during the study period (95\% confidence interval [Cl] 1.4 to 2.0 ) (Table 2). Physicians in older age categories had higher odds of retiring compared with those in the younger age groups (e.g., for age $\geq 75$ v. 56-59 yr, odds ratio [OR] $12.0,95 \% \mathrm{Cl} 9.3$ to 15.4 ). Physicians with a medical specialty (OR $1.2,95 \% \mathrm{Cl} 1.0$ to 1.4 )

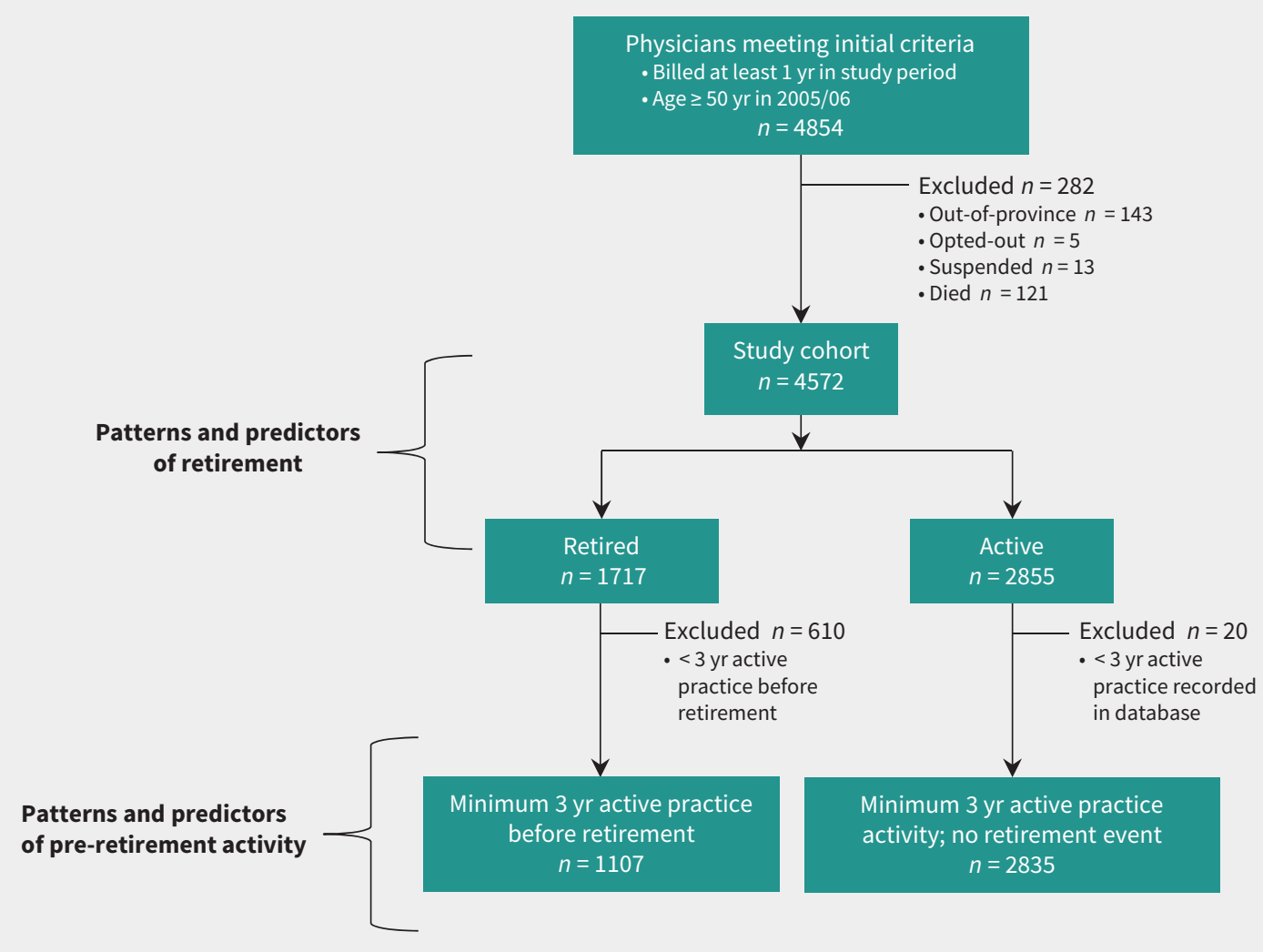

Figure 1: Cohort selection for a study of physician retirement and pre-retirement activity. 
and those with a laboratory or imaging specialty (OR 1.9, 95\% $\mathrm{Cl} 1.5$ to 2.5 ) had significantly higher age-specific odds of retirement compared with family physicians. Physicians whose practices were located in rural areas also had higher age-specific odds of retirement compared with those located in metropolitan centres (OR $1.6,95 \% \mathrm{Cl} 1.3$ to 2.0 ). We found no difference in the odds of retirement by location of training (Canadian $\mathrm{v}$. international).

\section{Age at retirement}

In our cohort, the average age at retirement was 65.1 (standard deviation 7.8) years. Controlling for the effects of physician specialty, age, practice location and training location, we found that female physicians retired 4.1 years earlier $(95 \% \mathrm{Cl}-4.9$ to $-3.2 \mathrm{yr}$ ) than their male counterparts (Table 3 ). Physicians practising in rural areas retired 2.3 years earlier $(95 \% \mathrm{Cl}-3.4$ to $-1.1 \mathrm{yr}$ ) than those practising in large metropolitan centres, whereas those who trained outside Canada retired 2.3 years later $(95 \% \mathrm{Cl} 1.6$ to 3.1) than those who trained within Canada. We found no difference in retirement age across specialty groups.

\section{Pre-retirement activity}

We had a minimum of 3 complete years of data for $3942(86.2 \%)$ of the 4572 physicians. Of these, 1107 (28.1\%) had a recorded retirement event. The physicians for whom we did not have the minimum 3 years of follow-up all retired within the first 3 years of the study period.

Patterns varied among those physicians who were retiring relative to those who were not retiring (Table 4). Retiring physicians were significantly more likely than non-retiring physicians to show patterns of slow $(18.7 \%$ v. $7.4 \%)$ or rapid $(21.1 \%$ v. $0.6 \%)$ reductions in activity, whereas non-retiring physicians were more likely

\begin{tabular}{|c|c|c|c|}
\hline Characteristic & $\begin{array}{l}\text { No. }(\%) \\
\text { in cohort }\end{array}$ & $\begin{array}{l}\text { No. }(\%) \text { of those } \\
\text { in full cohort } \\
\text { who retired }\end{array}$ & $\begin{array}{c}\text { Age at retirement (of } \\
\text { those who retired), } \\
\text { yr, mean } \pm \text { SD }\end{array}$ \\
\hline Total & 4572 & $1717(37.6)$ & $65.1 \pm 7.8$ \\
\hline \multicolumn{4}{|l|}{$\operatorname{Sex}^{*}$} \\
\hline Male & $3658(80.0)$ & $1351(36.9)$ & $66.0 \pm 7.7$ \\
\hline Female & $914(20.0)$ & $366(40.0)$ & $61.9 \pm 6.7$ \\
\hline \multicolumn{3}{|l|}{ Age group in 2012, yr† } & \multirow[t]{6}{*}{ NA } \\
\hline $56-59$ & $1033(22.6)$ & $243(23.5)$ & \\
\hline $60-64$ & $1346(29.4)$ & $361(26.8)$ & \\
\hline $65-69$ & $1120(24.5)$ & $423(37.8)$ & \\
\hline $70-74$ & $555(12.1)$ & $317(57.1)$ & \\
\hline$\geq 75$ & $518(11.3)$ & $373(72.0)$ & \\
\hline \multicolumn{4}{|l|}{ Specialty $\ddagger$} \\
\hline Primary care & $2294(50.2)$ & $796(34.7)$ & $65.7 \pm 7.3$ \\
\hline Medical & $1113(24.3)$ & $429(38.5)$ & $65.2 \pm 7.9$ \\
\hline Surgical & $827(18.1)$ & $325(39.3)$ & $66.1 \pm 7.6$ \\
\hline Laboratory/imaging & $338(7.4)$ & $167(49.4)$ & $65.1 \pm 7.0$ \\
\hline \multicolumn{4}{|c|}{ Practice rurality in $2012 \S 9$} \\
\hline Metropolitan & $2976(65.1)$ & $1025(34.4)$ & $66.0 \pm 7.5$ \\
\hline Urban-dominated & $992(21.7)$ & $377(38.0)$ & $65.4 \pm 7.7$ \\
\hline Rural-dominated & $480(10.5)$ & $195(40.6)$ & $64.0 \pm 7.2$ \\
\hline \multicolumn{4}{|l|}{ Location of training ${ }^{\star \star}$} \\
\hline Canada & $2925(64.0)$ & $1069(36.5)$ & $64.3 \pm 7.3$ \\
\hline International & $1647(36.0)$ & $648(39.3)$ & $66.6 \pm 8.0$ \\
\hline \multicolumn{4}{|c|}{ 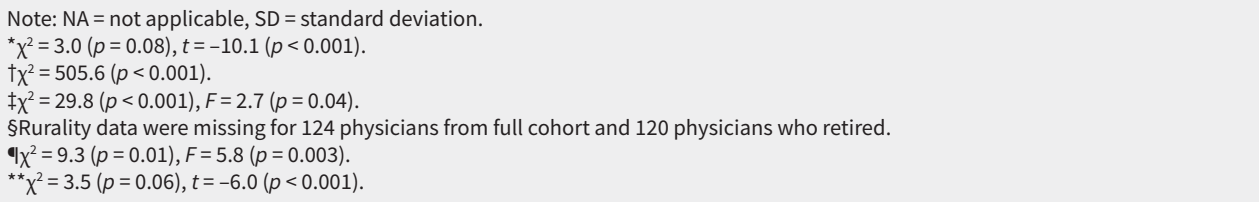 } \\
\hline
\end{tabular}


than retiring physicians to maintain their activity levels $(77.7 \% \mathrm{v}$. $38.1 \%)(p<0.001)$. Of the 1107 retiring physicians, $440(39.7 \%)$ reduced their practice activity levels between $10 \%$ and $90 \%$ in the years preceding retirement. We found no significant differences in pre-retirement activity across demographic or clinical characteristics (Table 5).

\section{Interpretation}

In this study, we found that the average age at retirement among BC physicians was 65.1 years. Physicians who were female and those who were practising in rural areas tended to retire earlier. We also found that physicians who were within 3 years of retiring exhibited different activity patterns than those who continued to practise. Many reduced their activity levels in the years immediately preceding retirement, some quite substantially. This finding is consistent with survey-based evidence that most physicians would prefer to retire gradually. ${ }^{13}$ The finding that many physicians reduced their activity levels in the years before retirement is of particular importance because it implies that physician resource plans relying on "head counts" of the physician population will overestimate "effective" or active physician supply.

Table 2: Logistic regression for odds of retirement

\begin{tabular}{|c|c|}
\hline Variable & OR $(95 \% \mathrm{CI})$ \\
\hline \multicolumn{2}{|l|}{ Sex } \\
\hline Male & 1.0 (ref) \\
\hline Female & 1.7 (1.4 to 2.0$)$ \\
\hline \multicolumn{2}{|l|}{ Age, yr } \\
\hline $56-59$ & 1.0 (ref) \\
\hline $60-64$ & $1.4(1.1$ to 1.7$)$ \\
\hline $65-69$ & 2.5 (2.0 to 3.1 ) \\
\hline $70-74$ & 5.9 (4.6 to 7.4$)$ \\
\hline$\geq 75$ & $12.0(9.3$ to 15.4$)$ \\
\hline \multicolumn{2}{|l|}{ Specialty } \\
\hline Primary care & 1.0 (ref) \\
\hline Medical & 1.2 (1.0 to 1.4 ) \\
\hline Surgical & $1.2(1.0$ to 1.4$)$ \\
\hline Laboratory/imaging & 1.9 (1.5 to 2.5$)$ \\
\hline \multicolumn{2}{|l|}{ Practice rurality } \\
\hline Metropolitan & 1.0 (ref) \\
\hline Urban-dominated & 1.3 (1.1 to 1.6$)$ \\
\hline Rural-dominated & 1.6 (1.3 to 2.0 ) \\
\hline \multicolumn{2}{|l|}{ Location of training } \\
\hline Canada & 1.0 (ref) \\
\hline International & $0.9(0.8$ to 1.1$)$ \\
\hline
\end{tabular}

Earlier retirement among rural physicians may be related to the higher rates of burnout observed in this population. ${ }^{18}$ It may also reflect the lower cost of living in rural areas, which provides greater ability to save for retirement. Regardless of the reason, early retirement in these communities is of particular concern, given that many rural areas are known to have substantial difficulties recruiting and retaining physicians. ${ }^{19,20} \mathrm{~A}$ smaller rural physician workforce could see increased rates of burnout and deterioration in the ability of those physicians to achieve work-life balance, while also exacerbating access issues for the residents of those communities.

Although there was a declining level of pre-retirement activity among many of the physicians who retired, we did not examine whether this decline was associated with a narrowing of clinical scope or merely a reduction in overall caseload. Other research has suggested that scope of practice for primary care physicians does narrow with age; ${ }^{10}$ however, we could locate no studies that addressed this question for other specialties. A narrowed scope of practice among family physicians in particular could have a disproportionate effect in rural and remote communities. ${ }^{21}$

We examined a complete cohort of physicians who were actively practising within in a specified jurisdiction. We used administrative payment data, including non-fee-for-service payments, covering $100 \%$ of clinical payments to these physicians through the BC Medical Services Plan to identify retirements and characterize pre-retirement activity. This approach represents both an important methodologic strength and an improvement on the existing body of evidence in this area, which has thus far been dominated by self-report surveys. We are aware of only 1 prior study that used physician payment data, and its methods did not allow inclusion of physicians who were paid by non-feefor-service methods. ${ }^{10}$ This type of payment may be particularly important to consider, given that physicians may adjust their mix of professional activities (e.g., moving away from fee-for-service clinical practice) in their later active years.

\section{Table 3: Linear regression for age at retirement}

\section{Variable}

Intercept

Sex, female

Specialty

Medical

Surgical

Laboratory/imaging

Practice rurality

Urban-dominated

Rural-dominated

Location of training, International
Relative age at retirement, $\mathrm{yr}^{*}$ $(95 \% \mathrm{Cl})$

66.0 (65.3 to 66.7$)$

$-4.1(-4.9$ to -3.2$)$

$-0.2(-1.1$ to 0.7$)$

$0.4(-0.6$ to 1.4$)$

$-0.7(-1.9$ to 0.6$)$

$-0.5(-1.4$ to 0.3$)$

$-2.3(-3.4$ to -1.1$)$

$2.3(1.6$ to 3.1$)$
Note: $\mathrm{Cl}=$ confidence interval.

*Age at retirement is presented relative to the reference category for each variable, as follows: for sex, reference category was male; for specialty, primary care; for practice rurality, metropolitan; for training location, Canada. 
Questions about physician retirement and pre-retirement activity are relevant to all jurisdictions in Canada and beyond. The methodology we have employed here could be deployed in other provinces with similar physician payment systems. Furthermore, we expect that physicians in general will have similar motivations for when and how to retire, and our results are therefore likely to be applicable to jurisdictions outside of BC. Indeed, there is some evidence to suggest similar patterns among physicians in Ontario. ${ }^{22}$

\section{Table 4: Activity patterns for non-retired (active) physicians and physicians who retired during the study period}

Activity pattern*; no. (\%) of physicians $\dagger$

$\begin{array}{lccccc}\text { Characteristic } & \text { Maintenance } & \text { Rapid decline } & \text { Slow decline } & \text { Increase } & \text { Total } \\ \text { Total } \neq & 2624 & 251 & 417 & 650 & 3942 \\ \text { Active } & 2202(77.7) & 18(0.6) & 210(7.4) & 405(14.3) & 2835 \\ \text { Retired } & 422(38.1) & 233(21.0) & 207(18.7) & 245(22.1) & 1107\end{array}$

*Activity patterns were defined as follows: maintenance $=$ limited change in activity $( \pm<10 \%)$, rapid decline $=$ activity decline of $25 \%$ to $<90 \%$, slow decline $=$ activity decline of $10 \%$ to $<25 \%$, increase $=$ activity increase $\geq 10 \%$. The table includes only physicians with at least 3 years of data.

tPercentages are calculated across rows.

$\mp \chi^{2}=833.8(p<0.001)$.

Table 5: Activity patterns for physicians who retired during the study period, in relation to various characteristics

\section{Activity pattern*; no. (\%) of physicians $\dagger$}

\begin{tabular}{|c|c|c|c|c|c|}
\hline Characteristic & Maintenance & Rapid decline & Slow decline & Increase & Total \\
\hline \multicolumn{6}{|l|}{ Sex } \\
\hline Male & $329(37.9)$ & $187(21.6)$ & $166(19.1)$ & $185(21.3)$ & 867 \\
\hline Female & $93(38.8)$ & $46(19.2)$ & $41(17.1)$ & $60(25.0)$ & 240 \\
\hline \multicolumn{6}{|c|}{ Age group in 2012, yr (\%)§ } \\
\hline $56-59$ & $52(34.9)$ & $35(23.5)$ & $25(16.8)$ & $37(24.8)$ & 149 \\
\hline $60-64$ & $109(41.4)$ & $50(19.0)$ & $47(17.9)$ & $57(21.7)$ & 263 \\
\hline $65-69$ & $103(34.7)$ & $73(24.6)$ & $59(19.9)$ & $62(20.9)$ & 297 \\
\hline $70-74$ & $71(35.0)$ & $45(22.2)$ & $37(18.2)$ & $50(24.6)$ & 203 \\
\hline$\geq 75$ & $87(44.6)$ & $30(15.4)$ & $39(20.0)$ & $39(20.0)$ & 195 \\
\hline \multicolumn{6}{|l|}{ Specialtyฯ } \\
\hline Primary care & $206(38.9)$ & $102(19.2)$ & $91(17.2)$ & $131(24.7)$ & 530 \\
\hline Medical & $111(40.2)$ & $54(19.6)$ & $50(18.1)$ & $61(22.1)$ & 276 \\
\hline Surgical & $68(34.2)$ & $48(24.1)$ & $50(25.1)$ & $33(16.6)$ & 199 \\
\hline Laboratory/imaging & $37(36.3)$ & $29(28.4)$ & $16(15.7)$ & $20(19.6)$ & 102 \\
\hline \multicolumn{6}{|c|}{ Practice rurality in $2012^{\star \star} \dagger \dagger$} \\
\hline Metropolitan & $271(39.0)$ & $135(19.4)$ & $139(20.0)$ & $149(21.5)$ & 694 \\
\hline Urban-dominated & $91(35.4)$ & $52(20.2)$ & $47(18.3)$ & $67(26.1)$ & 257 \\
\hline Rural-dominated & $43(39.8)$ & $29(26.8)$ & $16(14.8)$ & $20(18.5)$ & 108 \\
\hline \multicolumn{6}{|l|}{ Training ¥¥ } \\
\hline International & $265(37.4)$ & $154(21.8)$ & $136(19.2)$ & $153(21.6)$ & 708 \\
\hline Canadian & $157(39.3)$ & $79(19.8)$ & $71(17.8)$ & $92(23.1)$ & 399 \\
\hline \multicolumn{6}{|c|}{ 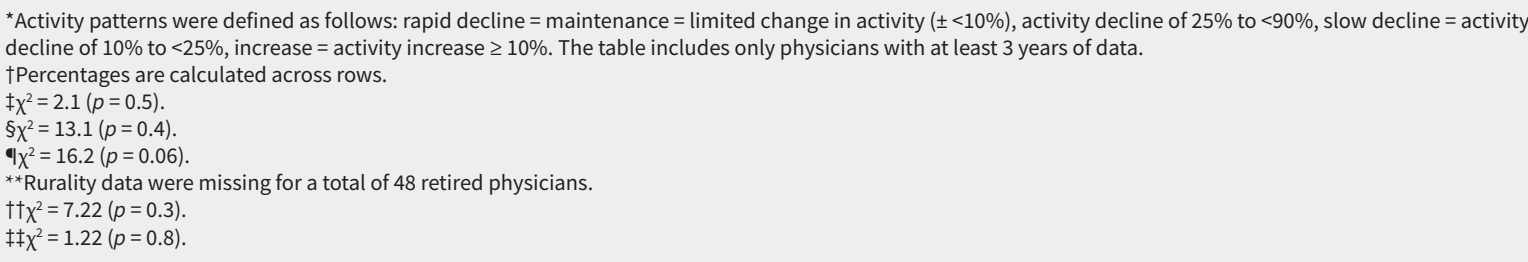 } \\
\hline
\end{tabular}




\section{Limitations}

Although the use of administrative payments data represents a methodologic advantage of this study, we did not measure factors shaping retirement decisions, such as job satisfaction and burnout, feelings of responsibility for patients, personal or family medical issues, psychologic distress, financial obligations and spousal workforce participation. ${ }^{3,4}$ Furthermore, because our data were limited to clinical activity, we could not examine whether physicians who left clinical practice did so to move on to other forms of employment, such as research or teaching positions.

\section{Conclusion}

Retirement and pre-retirement activity represent complex decisions for physicians, and pose challenges for decision-makers charged with health human resources planning. We found that BC physicians are retiring earlier than licensure data would imply, and many are reducing their practice activity in the years preceding retirement. Current planning efforts that rely on physician licensure data are vulnerable to overestimation of physician supply, because they do not account for physicians who are maintaining an active licence while no longer practising or the reduction in workload associated with the pre-retirement years.

\section{References}

1. Birch S, Kephart G, Tomblin-Murphy G, et al. Human resources planning and the production of health: a needs-based analytical framework. Can Public Policy 2007;33(Suppl 1):S1-16.

2. Silver MP. Critical reflection on physician retirement. Can Fam Physician 2016;62:783-4.

3. Radl J, Himmelreicher RK. The influence of marital status and spousal employment on retirement behavior in Germany and Spain. Res Aging 2015; 37:361-87.

4. Silver MP, Hamilton AD, Biswas A, et al. A systematic review of physician retirement planning. Hum Resour Health 2016;14:67.

5. Maguiness S, Searles GE, From L, et al. The Canadian Dermatology Workforce Survey: implications for the future of Canadian dermatology - Who will be your skin expert? J Cutan Med Surg 2004;8:141-7.
6. Davidson JM, Lambert TW, Parkhouse J, et al. Retirement intentions of doctors who qualified in the United Kingdom in 1974: postal questionnaire survey. J Public Health Med 2001;23:323-8.

7. Farley FA, Kramer J, Watkins-Castillo S. Work satisfaction and retirement plans of orthopaedic surgeons 50 years of age and older. Clin Orthop Relat Res 2008;466:231-8.

8. A survey of America's physicians: practice patterns and perspectives. The Physicians Foundation; 2012. Available: www.physiciansfoundation.org/uploads/default/ Physicians_Foundation_2012_Biennial_Survey.pdf (accessed 2017 June 15).

9. The College of Family Physicians of Canada; Canadian Medical Association; Royal College of Physicians and Surgeons of Canada. 2013 National Physician Survey. Mississauga (ON): National Physician Survey; 2013. Available: http:// nationalphysiciansurvey.ca/surveys/2013-survey/ (accessed 2016 May 24).

10. Pong RW. Putting away the stethoscope for good? Toward a new perspective on physician retirement. Spending and health workforce. Ottawa: Canadian Institute for Health Information; 2011. Available: https://secure.cihi.ca/estore/productFamily .htm?locale=en\&pf=PFC1609 (accessed 2017 June 15).

11. Rittenhouse DR, Mertz E, Keane D, et al. No exit: an evaluation of measures of physician attrition. Health Serv Res 2004;39:1571-88.

12. Petterson SM, Rayburn WF, Liaw WR. When do primary care physicians retire? Implications for workforce projections. Ann Fam Med 2016;14:344-9.

13. Pannor Silver M, Easty LK. Planning for retirement from medicine: a mixedmethods study. CMAJ Open 2017;5:E123-9.

14. British Columbia Ministry of Health. Medical Services Plan (MSP) payment information file. Version 2. Victoria: Population Data BC; 2013.

15. British Columbia Ministry of Health. Alternative Payments Program database. Victoria: Population Data BC; 2013.

16. College of Physicians and Surgeons of British Columbia. Medical Services Plan physician database. Victoria: Population Data BC; 2013.

17. CMA and CA: detailed definition. Ottawa: Statistics Canada; 2015. Available: www.statcan.gc.ca/pub/92-195-x/2011001/geo/cma-rmr/def-eng.htm (accessed 2017 June 27).

18. Thommasen HV, Lavanchy M, Connelly I, et al. Mental health, job satisfaction, and intention to relocate. Opinions of physicians in rural British Columbia. Can Fam Physician 2001;47:737-44.

19. Rosenblatt RA, Hart LG. Physicians and rural America. West J Med 2000;173:348-51.

20. Rourke J. Increasing the number of rural physicians. CMAJ 2008;178:322-5.

21. Pong RW, Pitblado JR. Geographic distribution of physicians in Canada: beyond how many and where. Ottawa: Canadian Institute for Health Information; 2006.

22. Simkin S, Dahrouge S. Measuring retirement: a workforce planning challenge [lecture]. Canadian Association for Health Services and Policy Research annual conference; 2016 May 10-12; Toronto.
Competing interests: Michael Law has received personal fees from Health Canada for activities outside the submitted work. No other competing interests were declared.

This article has been peer reviewed.

Affiliations: Centre for Clinical Epidemiology and Evaluation (Hedden), Vancouver General Hospital, Vancouver, BC; Faculty of Health Sciences (Lavergne), Simon Fraser University, Burnaby, BC; Centre for Health Services and Policy Research (McGrail, Law, Cheng, Ahuja, Barer), University of British Columbia, Vancouver, BC

Contributors: Lindsay Hedden was responsible for conception and design of the study, produced the plan for data analysis, interpreted the results, and drafted the article and the response to reviewer and editor comments. Ruth Lavergne, Kim McGrail, Michael Law and Meghan Ahuja contributed to the study design, interpretation of the results and critical revision of the arti- cle. Lucy Cheng conducted the data analysis, contributed to the interpretation of results and helped with critical revision of the article. Morris Barer conceived the project, designed and submitted the overall project for grant funding, and contributed to interpretation of the results and to critical revision of the article. All authors gave final approval of the version to be published and agreed to be accountable for all aspects of the work.

Funding: This study was funded by a Canadian Institutes of Health Research Operating Grant (FRN 104086).

Disclaimer: All inferences, opinions and conclusions drawn in this manuscript are those of the authors, and do not reflect the opinions or policies of the database stewards.

Accepted: July 27,2017

Correspondence to: Lindsay Hedden, lindsay.hedden@ubc.ca 